\title{
NEW SPECIES OF THE ANT GENUS MYOPIAS (HYMENOPTERA: FOR MICIDAE: PONERINAE)
}

\author{
By Robert B. Willey ${ }^{1}$ AND William L. Brown, JR. ${ }^{2,3}$
}

The work reported upon here began in the early 1950's as a revision of genus Myopias, including as a synonym Trapeziopelta. For a year or more it served as the trial focus of RBW's doctoral thesis research, until his interests shifted into other channels, and he laid the revisionary work aside. Meanwhile, WLB's interest in the revision continued, but he had no opportunity at that time to do much more than supervise the drafting of a set of illustrations by artist Nancy Buffler-many of which are now offered here-and to make some of the dissections of mouthparts, etc.

As WLB's work on the reclassification progressed for over 25 years through the tribes of subfamily Ponerinae, much new material was added to what had been available for the original Myopias study, and additional new synonymies and new species were discovered, as well as valuable information on the larvae, males, distribution and bionomics of species new and old. Even the status of Myopias as a genus apart from Pachycondyla came into question. Although in some ways it would be best if the old findings to which we both contributed could simply be incorporated in the reclassification part dealing with tribe Ponerini $s$. str., there seemed in this course no convenient way to recognize the legitimate claim of RBW to authorship based on the considerable amount of work he had done on Myopias in 1955.

The compromise reached sees the larger Myopias review, with keys to species and discussions of synonymy, biology, etc. to be included in Brown's forthcoming Part VII of "Contributions toward a Reclassification of the Formicidae," while descriptions of the new species included in various drafts of our joint manuscript of the

\footnotetext{
'The University of Illinois at Chicago Circle, Biological Sciences, P.O. Box 4348, Chicago, IL 60680.

${ }^{2}$ Department of Entomology, Cornell University, Ithaca, NY 14853. (Address correspondence here.)

${ }^{3} \mathrm{~A}$ report of research from the Cornell Agricultural Experiment Station. Research supported by National Science Foundation Grant DEB-8003722.

Manuscript received by the editor March 15, 1983
} 
1950's are presented here, together with a few notes on variation, on bionomics, and on the distribution of certain species. Figures of some old species are included with those of the new ones.

\section{Collections and Collectors, with Abbreviations}

The main collection used is that of the Museum of Comparative Zoology at Harvard University, Cambridge, Massachusetts (MCZ), for Myopias based mainly on collections by Eric Mjöberg, Edward O. Wilson, James W. Chapman, William L. Brown, Jr. and Philip S. Ward. Secondary sources were the British Museum (Natural History) in London (BMNH), collected by Barry Bolton and others, and the Australian National Insect Collection at Canberra (ANIC), collected by Robert W. Taylor and others. For the collectors named above, only surnames are cited in the text. Our thanks go to all who provided us with specimens.

The drawings provided here were mostly done during the mid1950's by Nancy Buffler. Fig. 4 is by James S. Miller. We are also grateful for a copy set of Edward Wilson's wonderful New Guinea field notes of 1955, which have yielded most of what we know about Myopias bionomics, here published for the first time.

\section{Measurements and Ratios}

Where series were available, measurements were usually taken on the largest and smallest (worker) specimens in each locality-series. The measurements and indices are mostly those standard in ant taxonomy for the past 30 years.

TL (total length) axial length of body, including closed mandibles; summed $\mathrm{ML}+\mathrm{HL}+\mathrm{WL}+$ petiole $\mathrm{L}+$ length of gaster.

HL (head length) maximum measurable length of head as seen in dorsal full-face view, using the anterior edges of the frontal lobes as the anterior reference point, and the posteriormost point or points of the cranial outline as the posterior reference point.

HW (head width) maximum measurable width of head, not including the eyes, as seen in dorsal full-face view.

CI (cephalic index) $\mathrm{HW} \times 100 / \mathrm{HL}$.

ML (mandibular extension) maximum measurable distance be- 
tween the most distal apex of the closed mandibles and the anterior edges of the frontal lobes, as seen in same (dorsal full-face) view from which HL is taken.

MI (mandibulo-cephalic index) $\mathrm{ML} \times 100 / \mathrm{HL}$.

MLO (mandibular outside length) maximum absolute chord length of left mandible measured from lateral insertion to apex.

CLL, (length, width of median clypeal lobe) as measured in dorsal CLW full-face view.

SL (scape length) chord length of antennal scape, excluding radicle.

SI (scape index) SL $\times 100 / \mathrm{HW}$

EL (eye length) maximum measurable length of facetted part of eye.

WL (trunk length) diagonal length of trunk as measured from side view, from anterodorsal slope of pronotum (excluding cervix) to most posterior extremity of propodeum.

Myopias gigas, new species

(Figures 1, 12)

Diagnosis, worker: A very large species of the $M$. loriai group, even larger than $M$. loriat, with proportionately longer mesonotum and petiolar node, and with the head dorsally, trunk dorsum and pleura of posterior section of trunk sharply and regularly striate; body otherwise prevailingly smooth and shining. Funicular segment II very long, longer than I.

Worker, holotype: TL 16.9, HL 2.50, HW 2.60 (CI 104), ML 2.26 (MI 90), SL 2.62 (SI 101), EL 0.45, WL 4.61, petiole L 1.7, hind femur L 3.7, hind tibia L $3.16 \mathrm{~mm}$.

This, the largest known species of Myopias, has the broad, posteriorly narrowed head of the loriai group; long, slender, curved mandibles and rather large eyes with many fine facets. A scape, when held straight back as seen in full-face view, surpasses the posterior border of the head by nearly $2 \frac{1}{2}$ times the apical scape width. The posterior border of the head is transverse and nearly straight, varying from very feebly concave to subsinuate in slightly different views. As in M. loriai, the median clypeal lobe is apically biconvex, with a shallow median notch; the lobe is shorter and broader than in $M$. loriai, and tapers slightly from base to apex. 
Antennal funicular segment II is longer than I, III and all other funicular segments except the apical, and it is 2.5 times longer than its maximum (apical) width. No differentiated antennal club.

Labrum with a sharp erect tooth at the apex of each labral lobe; no median labral tubercle. Palpi concealed, not seen. Mandibles as shown in Figure 1; apical tooth followed closely basad by 2 coarse denticles and a blunt tooth; middle tooth followed basad by a low, rounded basal angle. Strix (mandibular groove) well-developed from base to apex.

Trunk long and robust; mesonotum longer than in loriai, but wider than long $(\mathrm{L} / \mathrm{W} \sim 0.7)$. Metanotum present as a deeply impressed groove, widening laterad on each end. In side view profile, pronotum strongly convex, although transversely impressed just in front of the raised, cariniform posterodorsal margin; mesonotum feebly convex and sloping downward behind, but its anterior margin raised slightly above the posterior pronotal margin, especially (as in the type) when the two somites are flexed against each other. Promesonotum (without cervix) and propodeum subequal in length; propodeum broadly convex from front to rear, with its declivity steeper than its dorsum, but passing into dorsum through a gentle curve. Mesopleural suture distinct and complete, moderately deeply impressed (more distinct than in $M$. loriai). Propodeal spiracle elongate and oblique, its opening about $2 \frac{1}{2}$ times longer than wide.

Petiole (Fig. 12) loaf-shaped, longer than broad and longer than high; exact shape of subpetiolar process, if any, not determined because the extreme anterior end of the segment is hidden by the coxae. Gaster long, gently downcurved, with a distinct constriction between first and second segments; dorsally viewed, second segments longer and a little wider than first. Sting long and strong, distinctly upcurved.

Dorsum of head completely finely and regularly striate in a longitudinal direction, the striae mesal to and behind the eyes tending to curve slightly outward. Dorsum and declivity of trunk similarly striate, but in a transverse direction, arching on pronotum. Sides of trunk behind pronotum with similar, oblique striation, continued from the propodeal dorsum through a curve. Remainder of head, body and appendages smooth and shining, including mandibles, cervical border of vertex and sides of pronotum. Coarse, spaced, 


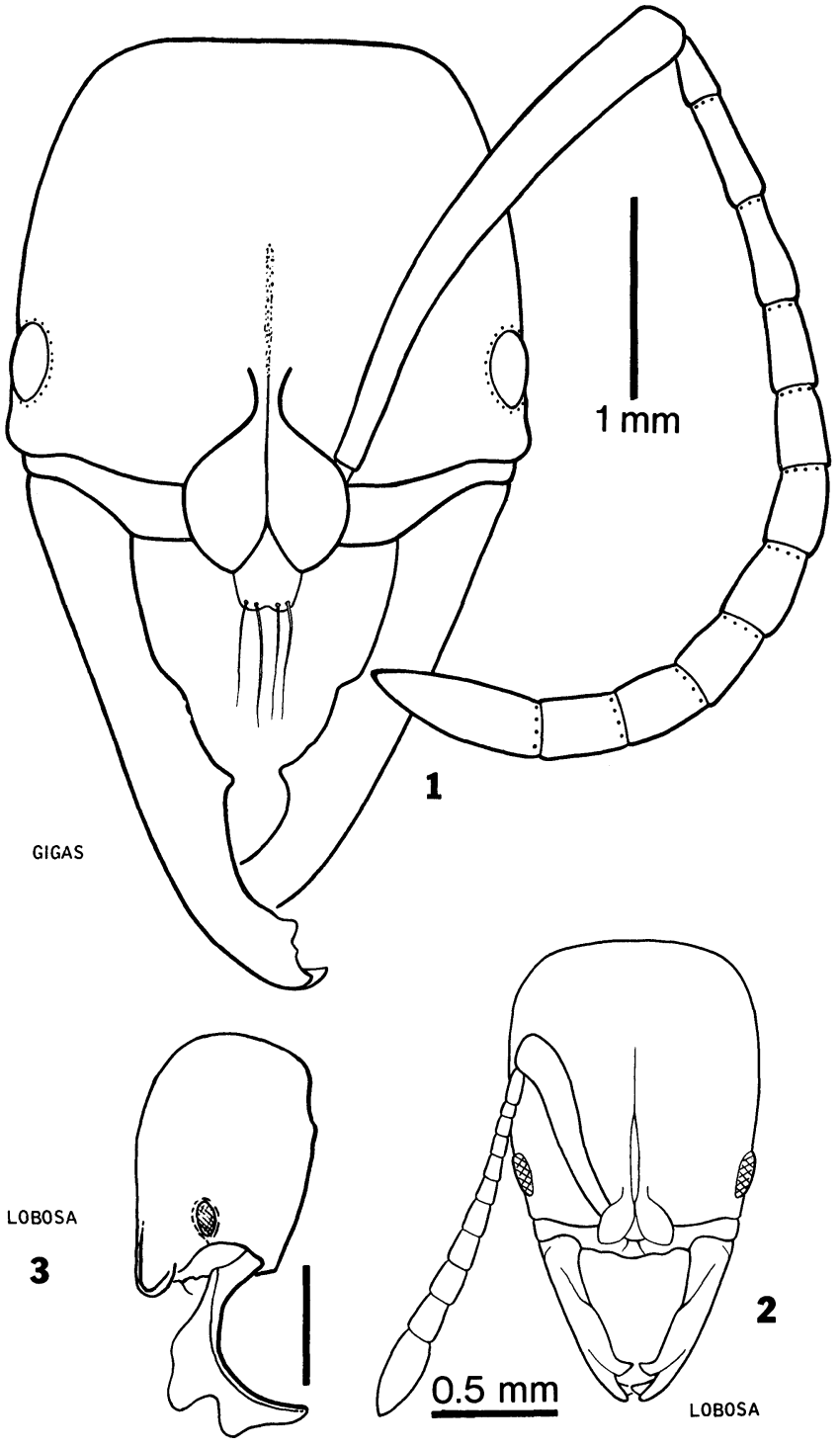

Figs. 1-3, Myopias spp., heads of workers, sculpture and pilosity omitted. Fig. 1, $M$. gigas holotype in full-face view. Fig. 2, M. lobosa, paratype in full-face view. Fig. 3, M. lobosa, another paratype in side view. Scale bars for Figs. 2 and 3 are $0.5 \mathrm{~mm}$. 
piligerous punctures are conspicuous in smooth areas, particularly the sides of the head, mandibles, femora and tibiae, petiole, and normally exposed surfaces of gastric terga.

Pubescence appressed and decumbent, generally very sparse, except on antennal flagella, coxae, tarsi, flexor surfaces of fore tibiae, flexor surfaces of mid femora, extensor surfaces of mid tibiae, and apex of hypopygium. Rather abundant erect or suberect, fine, tapered hairs, from short to over $0.5 \mathrm{~mm}$ long, occur on almost all normally exposed surfaces of body and appendages. Color deep reddish brown, appendages mainly clear light red.

Holotype (MCZ) a unique worker from Dobodura, Papua New Guinea (P.J. Darlington leg.).

This magnificent species is even larger than $M$. loriai, and has very different sculpture, but the two forms are obviously closely related. Because of the long mandibles and large size, we guess that $M$. gigas may be a millipede predator, but we have no direct evidence of feeding behavior for this species.

\section{Myopias julivora new species}

(Figs. 5, 22)

Diagnosis, worker: Similar to M. tenuis, but larger (HW 0.801.01 ), with relatively longer mandibles and antennae, $\mathrm{MI}>65$, scapes overreaching posterior border of head (when held straight back, full face view) by about their own apical width to nearly twice their apical width; all antennomeres longer than broad. Shafts of mandibles approximately straight over middle half of their length.

Worker, holotype: TL 6.2, HL 1.04, HW 0.94 (CI 90), ML 0.73 (MI 70), MLO 1.01, SL 0.90 (SI 96), EL 0.09, WL 1.74, hind femur L 1.00, hind tibia L $0.94 \mathrm{~mm}$.

Worker, paratypes $(n=6$ of 34 representing 7 colonies from 6 localities, including largest and smallest specimens): TL 5.8-6.7, HL 0.91-1.14, HW 0.81-1.01 (CI 88-90), ML 0.62-0.83 (MI 66-73), MLO 0.86-1.14, SL 0.86-1.09 (SI 96-108), EL 0.06-0.10, WL 1.66-1.93, hind femur L 0.89-1.15, hind tibia L $0.87-1.12 \mathrm{~mm}$.

Description limited to details not covered in diagnosis and measurements. Median frontal sulcus extends approximately to middle of $\mathrm{HL}$, followed posteriad after a gap by a shallow pit marking location in queen of anterior ocellus; this pit is usually absent in $M$. tenuis, but is occasionally faintly indicated there. Compound eye 
essentially reduced to a single convex lens, but at high magnifications, traces of an ommatidial grid can be made out; reduction approaches the state in $M$. tenuis, but does not go quite so far. Median clypeal lobe trapezoidal, widest near apex (CLL 0.12, CLW $0.16 \mathrm{~mm}$ ), but by optical illusion may seem as long as or longer than wide; free corners rounded; anterior margin straight, convex, or even slightly sinuate. Basal oblique mandibular groove (strix) sublateral in origin, difficult to see in dorsal view, but distinct with its ventrolateral extension in side view. Submedian tooth situated in seventh tenth of the shaft length, counting from base. Basal angle obsolete.

The upturned tooth on each labral lobe and 3,3 palpal segmentation formula are as in tenuis.

Trunk formed much as in $M$. tenuis; promesonotum subequal in length to propodeum; side view outline rather low and weakly convex, with a distinctly, but not deeply, impressed metanotal groove; propodeal dorsum only feebly convex, and sometimes very feebly impressed near midlength. Petiolar node slightly longer than broad, about as broad as long, or slightly broader than long, in different series (as in $M$. tenuis also), summit convex, slightly higher behind.

Gaster with first segment strongly rounded above, tergum rising caudad; segment II distinctly constricted in front at juncture with its acrotergite; about as high at maximum height as segment $I$, and slightly wider. As seen from above, anterior margin of segment I straight or feebly convex; shallowly concave in Vanimo worker (and queen). Sting long (extruded up to $0.6 \mathrm{~mm}$ ), sharp, upcurved.

Sculpture prevailingly smooth and shining; punctures minute and widely spaced, more numerous and coarser on head, especially in Vanimo worker and queen, and on propodeum, but even here still obscure. Pilosity of uneven length, fine, tapered, erect to suberect hairs, mostly 0.05 to $0.30 \mathrm{~mm}$ long; pubescence decumbent to suberect, very dilute on anterior dorsum of head, but more abundant on antennae and legs, especially extremities.

Color averaging lighter than in fully pigmented $M$. tenuis workers, light to medium brownish red to dark brownish red, light orange brown in some workers, possibly callow. Appendages usually lighter, more yellowish, than basic body color.

Worker variation, as mostly discussed already above, involves mainly size-related features and shape of clypeal lobe, distinctness 
and density of the obscure puncturation, length and degree of apical taper of petiolar node, size and pigmentation of compound eyes, length of antennal scapes, and depth of body color.

Queen, dealate (from type nest series, Wilson No. 905), TL 7.1, HL 1.10, HW 0.97 (CI 88), ML 0.74 (MI 67), MLO 1.02, SL 0.96 (SI 99), EL 0.26, WL $2.03 \mathrm{~mm}$. Combined measurements for the largest queen specimen (above), another queen from the type locality, colony No. 1048, and a smaller queen from near Vanimo, are: TL 5.6-7.1, HL 0.93-1.10, HW 0.84-0.97 (CI 88-90), ML 0.63-0.76 (MI 67-72), MLO 0.87-1.03, SL 0.87-0.96 (SI 99-104), EL 0.220.26 , WL $1.78-2.03 \mathrm{~mm}$.

The queen differs from accompanying workers by the usual ponerine characters, and is also darker in color, prevailingly piceous, or even blackish in the Vanimo specimen. On trunk, centers of scutum and scutellum are infuscated, while marginal areas of these and other sclerites are lighter and more reddish. Appendages lighter, more yellowish.

Male unknown.

Described from material representing seven separate collections from six localities in Papua New Guinea. Holotype (MCZ) from Wilson's colony No. 905, lower Busu River, Huon Peninsula, Papua New Guinea, 3 May 1955, a nest in rain forest in a small Zorapterastage rotten log, in a part of the log somewhat raised off the ground, containing one queen, about 30-40 workers, and brood of all stages, with pupae predominating. Abundant remains of millipedes were found in the brood chamber and galleries leading away. One fresh millipede corpse was among larvae; the prey all seemed to belong to one kind.

Another colony (Wilson No. 1048) also came from the lower Busu River tract, 15 May 1955, from cavities in an old, hard polypore fungus growing on a large Passalus-stage log, containing a queen and about 75 workers, plus abundant brood of all stages, without notable preponderance. Half of a freshly dead millipede was found with the brood; the midden remains were collected (but later lost with the nest residue in alcohol).

A worker and a dealate queen were found in lowland $(40 \mathrm{~m})$ rain forest next to the quarry at $\mathrm{Km} 2$ on the Bewani Road, near Vanimo, West Sepik District, Papua New Guinea, 27 February 1981, leg. Brown (No. 81-48). The nest was in a small rotten stick 
lying on the ground, and contained larvae as well as the remains of small millipede prey. (Paratypes in MCZ, BMNH, ANIC, etc.)

In addition, single strays come from three widespread localities: Dobodura, March to July 1944, leg. P. J. Darlington, Jr.; Iora Creek, $17 \mathrm{~km}$. S. of Kokoda at $1400 \mathrm{~m}$, leg. Ward (No. 1831) rotten $\log$, montane rain forest; Baiyer River, Western Highlands, about $1200 \mathrm{~m}, 6$ July 1974, leg. S. Peck, berlesate B-281. The last specimen is the largest one of the species seen; it is also the darkest in color, has somewhat coarser punctures than usual on the head, and has the longest scapes, so that it might be thought transitional to M. media, but the form of the mandibles and clypeal lobe is typical for julivora.

The name of this species derives from the Latin julus, a millipede, and vorare, to devour. The new species is close to the very variable $M$. tenuis, but seems constantly distinct from it, even where the two species occur in intimate sympatry, as they do in the Busu River tract. For relationship to $M$. media, see under that species below.

\section{Myopias media new species}

(Figs. 6, 23)

Diagnosis, worker: member of tenuis group, very similar to $M$. julivora in habitus, color, etc., but larger, head wider, with more robust and more strongly curved mandibles, the submedian tooth situated closer to the midlength (at the seventh twelfth from base along MLO). Antennae long; scapes overreaching posterior border of head (when held straight back) by nearly twice their apical width.

Worker, holotype: TL 7.6, HL 1.25, HW 1.24 (CI 99), ML 0.93 (MI 74), MLO 1.26, SL 1.27 (SI 102), EL 0.13, WL 2.20, hind femur L 1.40, hind tibia L $1.35 \mathrm{~mm}$.

Details additional to diagnosis: Viewed at apparent full-face, posterior border of head feebly convex, almost straight, but even a slight tilting of the cranium forward yields a concave border, and an increase in HL to 1.30, so that from this view, CI would be about 95 . Anterolateral corners of head more prominent (at a lower level of focus), so that, excluding eyes, head is widest just behind clypeus. Median frontal sulcus continuing past mid-HL to include anterior clypeal pit. Eyes as in M. julivora, but relatively a little larger, and with remnants of facetting a bit more evident. Median clypeal lobe very obviously broader than long (CLL 0.13 , CLW 0.20), with 
weakly concave sides, nearly straight apical margin, and one free corner rounded, the other rectangular. Mandibles thicker, particularly in the stretch between the obsolescent basal angle and the submedian tooth, which is also feebly convex mesally (concave or straight along mesal margin in M. julivora). Labrum toothed as in M. julivora.

Sculpture as in $M$. julivora, but small, widely spaced punctures (diameter 0.01-0.02 $\mathrm{mm}$ ) are perhaps more distinct on head and trunk. A small patch of longitudinal costulation lies below spiracle on side of propodeum (as in M. julivora). Posterior corners of propodeum less broadly rounded, tending more towards angularity, both in side and dorsal views, than in M. julivora, and both the pilosity and pubescence seem to be less copious and a trifle longer.

Color deep brownish red; legs yellowish red; antennae and mandibles dark yellowish brown.

Holotype and only known specimen (MCZ) a stray collected from rotten wood at Joangeng, a village in the Mongi River Watershed of the Huon Peninsula, Papua New Guinea, at about 1500 m, 7-8 April 1955, in montane rain forest, leg. Wilson, No. 752.

We describe this species with some misgiving because it is based on a unique, and because it is so similar to M. julivora, especially to the largest (Baiyer River) specimen of the lattter. The mandibles, however, differ enough that we feel inclusion of the big Joangeng specimen in $M$. julivora would unduly strain the concept of that species. Further collections will of course help to demonstrate whether our decision is correct or not. The name media refers to the size of the body, intermediate in the tenuis group between $M$. tenuis and such large forms as loriai and gigas.

\section{Myopias concava new species}

(Figs. 4, 18)

Diagnosis, worker and queen: A medium-sized, stout-bodied species with head slightly broader than long, widest just behind eyes. Median labral tooth absent, but an erect apical tooth on each labral lobe. Eyes of worker large and multifacetted, occupying more than a quarter of the length of the sides of the head. Posterior margin of head weakly concave; sides convex. Median lobe of clypeus distinct but very short, rectangular. Mandibles short and stout, each with 2 
small teeth at apex, 2 large blunt teeth basad of these, and an obtusely rounded basal angle. Antennal scapes overreaching posterior margin of head. Trunk compact, promesonotum and propodeum subequal in length, forming separate weak convexities meeting at a distinct and depressed metanotal groove. Petiolar node massive, subcuboidal, broader than long. Anterior face of gastric segment I weakly concave as seen from dorsal view. Integument prevailingly smooth and shining, but with abundant, coarse piligerous foveolae, sometimes contiguous on head, and tending to become elongate on first two gastric terga. Color brownish red.

Worker, holotype: TL 7.1, HL 1.25, HW 1.31 (CI 105), ML 0.71 (MI 57), MLO 1.26, SL 1.11 (SI 85), EL 0.33, WL 2.16, hind femur L 1.25 , hind tibia L $1.20 \mathrm{~mm}$.

Worker, paratypes $(\mathrm{n}=6$ of 42 from 4 colonies, including largest and smallest specimens): TL 6.5-8.6, HL 1.17-1.43, HW 1.21-1.47 (CI 100-105), ML 0.67-0.81 (MI 53-66), SL 1.00-1.24 (SI 83-88), EL 0.30-0.40, WL 2.00-2.46 mm.

Head broader than long, with sides convex, broadest immediately behind eyes, and narrowed slightly in front of eyes; posterior border broadly and shallowly concave. (The head can be lengthened slightly by tilting it forward from the full-face plane; this has the effect of foreshortening the mandibles and deepening the concavity of the posterior margin, and of course decreasing CI.) Eyes large and convex, with about 18-19 ommatidia in the longest diagonal row, each eye occupying nearly $3 / 10$ of the length of its side of the head, situated about $2 / 3$ its own length from mandibular insertion.

Clypeal lobe distinctly projecting but short, rectangular, more than twice as broad as long, with parallel sides, a nearly straight anterior margin, and subrectangular free corners (in Wau Creek series, anterior margin weakly convex, free corners more rounded). Labrum with the transverse ridge feebly sinuate in front view, lacking a median tubercle; labral lobes each with a small upturned apical tooth. Maxillary palpi each 3-merous; basal segment broadest, with one subapical lateral sensillum; apical segment with a single apical sensillum. Labial palpi each with 3 subequal segments; basal segment with 2 adjacent submedian sensilla; II with one subapical lateral sensillum; III with the same, plus 2 apical sensilla.

Mandibles stout, gently bowed, each with two small teeth at apex, a blunt tooth near apical quarter of ML, a large, blunt submedian 


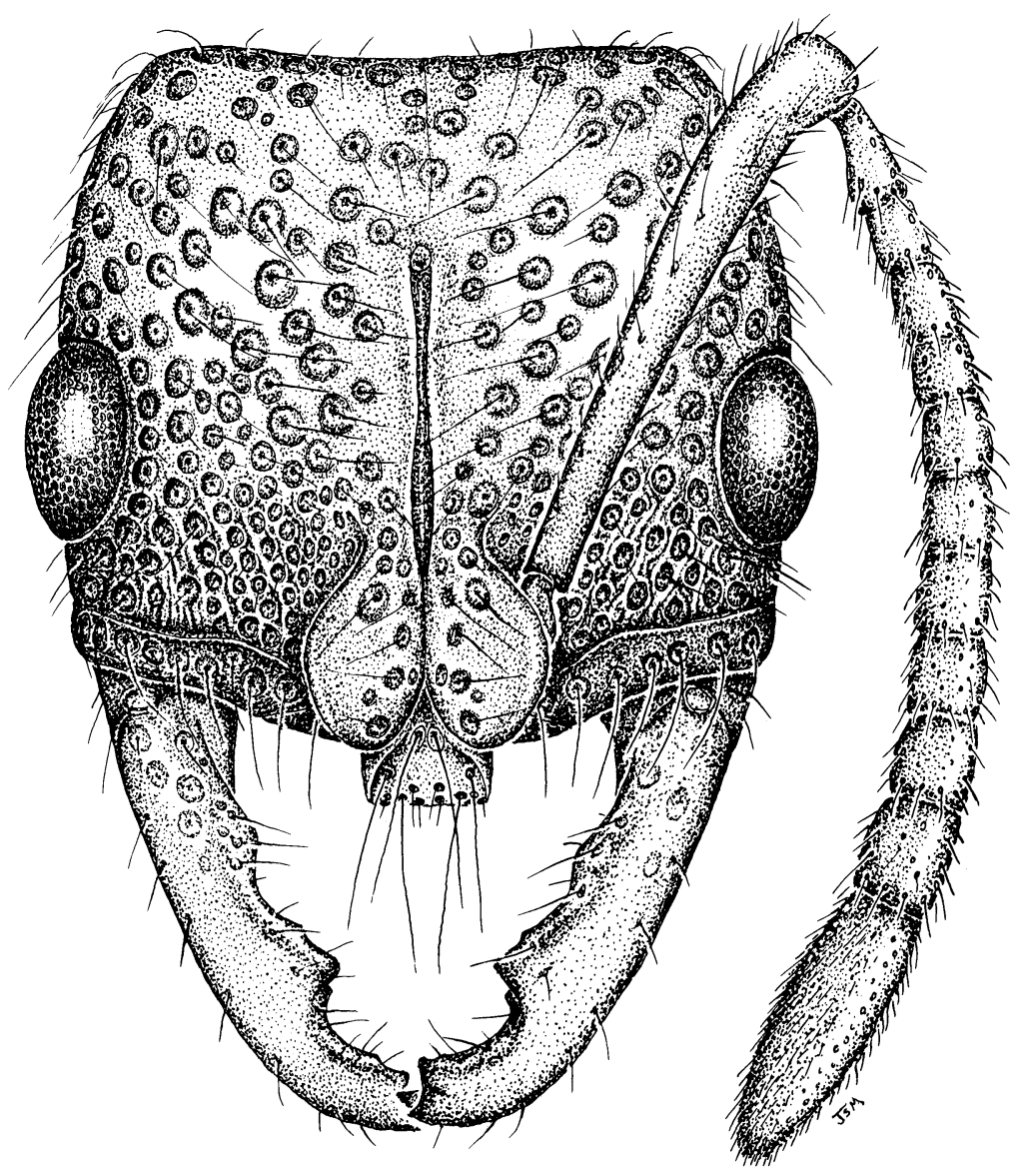

Fig. 4, Myopias concava, head of worker paratype in full-face view. Scale bar is 0.5 $\mathrm{mm}$.

tooth, and a distinct but rounded basal angle. Oblique groove at base continued as a broad lateral-marginal groove (strix) to apex.

Median frontal sulcus of head extends to or nearly to posterior quarter of head length. Scapes gently curved, moderately incrassate apicad, overreaching posterior border by more than their apical width when head is viewed full-face. Funiculus relatively slender, all segments longer than broad; apical segments not forming a club; 
pedicel (funiculus I) longer than II as 4:3.

Trunk robust, with a weakly convex dorsal profile as seen from the side; propodeum subequal in length to promesonotum; mesonotum convex, about half as long as propodeal dorsum, and separated from it by a distinct but only moderately impressed metanotal groove. Propodeal dorsum only very feebly convex, passing into declivity through a rounded obtuse angle. Declivity almost flat, with bluntly subangular lateral edges, densely punctate in upper $2 / 5$, smooth and shining below this.

Petiolar node massive, subcuboidal, slightly higher and broader behind than it is long (disregarding sternital keel); front and rear faces flat, vertical, dorsal face gently convex and sloping slightly anteriad. Sternite forming a sharp, recurved (hooklike) anterior subpetiolar process, followed by a short concavity and then by a long, low, feebly convex keel.

Postpetiolar segment (gaster I) wider than long (roughly about as 4:3) and very slightly wider than gaster II; anterior face abruptly vertical, its dorsal margin gently concave as seen from above. Gaster II (ignoring acrotergite normally covered by gaster I) longer than I, but still not quite as long as wide. In side view, these two segments are about equally high. Apical gastric segments short, as usual; sting very long (and is found extended up to $1.1 \mathrm{~mm}$ in some paratype workers), gently upcurved. Gonostylus (in paratypes) long, 2-merous.

Body basically smooth and shining, but sown with deep, conspicuous, piligerous foveolae, mostly round or oval on the head (here 0.03 to $0.09 \mathrm{~mm}$ in diameter), trunk and petiole, becoming more elongate axially on first two gastric terga. Foveolae on head smaller and more crowded, forming oblique chains interspersed with costulae between eyes and frontal lobes, but those caudad of eyes larger, forming vague, oblique chains, separated on the average by their diameters near the cephalic midline, but smaller and more crowded., often subcontiguous laterad and caudad. Foveolae more widely spaced on trunk and petiole, especially near midline and on sides of pronotum; metapleura with a few coarse longitudinal-oblique costae. Petiole and postpetiole (first gastric segment) with smaller, crowded foveolae on sides and ventrad, but on second gastric segment, the foveolae become very sparse apicad and ventrad, the surfaces here virtually smooth, except for a crowded band of small foveolae along the apical margin. Apex of gaster, antennal scapes, 


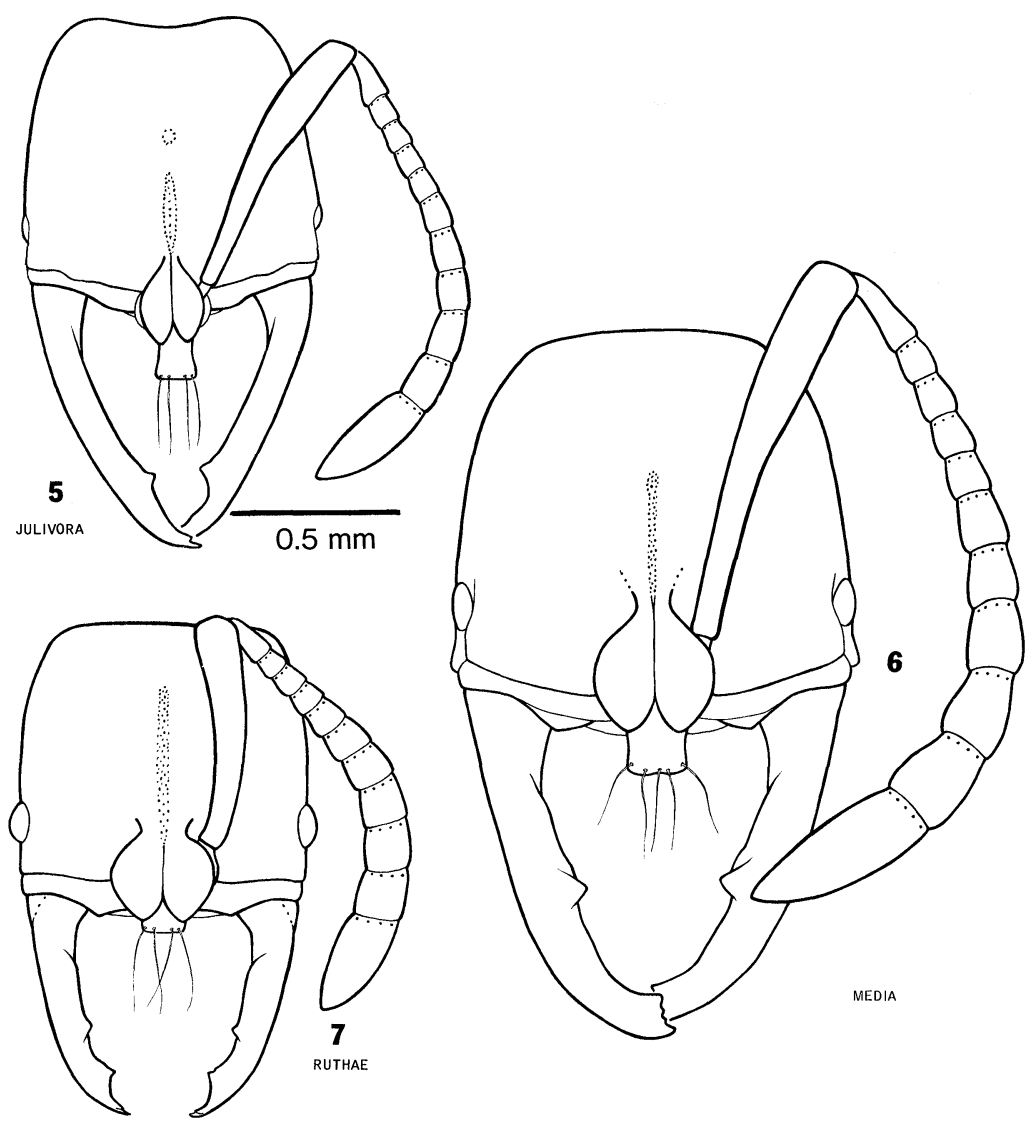

Figs. 5-7, Myopias spp., heads of workers in full-face view, sculpture and pilosity omitted. Fig. 5, M. julivora paratype. Fig. 6, M. media holotype. Fig. 7, M. ruthae holotype, All to same scale; bar is $0.5 \mathrm{~mm}$.

mandibles and legs prevailingly smooth, with spaced piligerous punctures.

Body and appendages clothed with numerous fine, tapered, decumbent to subdecumbent hairs, mostly each issuing from a foveola, and nearly all 0.10 to $0.25 \mathrm{~mm}$ long (up to $0.30 \mathrm{~mm}$ on anterior clypeal lobe).

Color rich, deep brownish red; legs a little lighter reddish.

Worker variation; apart from size, mainly involves slight differ- 
ences among nest series in the shape of the median clypeal lobe (convex vs. straight apical margins), density and size of individual foveolae of sculpture, and depth of coloration.

Queen, dealate, from holotype nest series, Wamuki: TL 8.2, HL 1.37, HW 1.50 (CI 109), ML 0.80 (MI 58), SL 1.20 (SI 80), EL 0.45, WL 2.61. Four additional queens range downwards in size slightly from this (Collection Nos. $887(n=3)$ and $990(n=1)$ from Busu River, the smallest having HW 1.33. A female from the Wau Creek series is ergatoid, but has HW about 1.50; this specimen lacks ocelli, but has small, blackened forewing stumps. The queens resemble the workers except in the caste difference usual for ponerines.

Male unknown.

Described from material from four separate nest series, all from what is now Papua New Guinea: holotype from Wamuki, $800 \mathrm{~m}$, on the Mongi River watershed, Huon Peninsula, 19-20 April 1955 (Wilson No. 844; MCZ). No. 844, a colony containing one queen and about 20 workers, was taken from a Zoraptera-stage rotten log in hill rain forest. Two colonies came from the area between the lower Busu and Bupu rivers, near Lae, at the base of the Huon Peninsula, in lowland rain forest (Wilson Nos. 887 and 990). No. 887 was a nest in a small Passalus-stage log, 28 April 1955, and included at least three queens. No. 990 was in a small $(10 \mathrm{~cm}$ diameter) rotten log with interior crumbling, but bark intact. It held 50-60 workers, two queens, eggs, larvae up to half-grown (no larger larvae) and one cocoon. The brood chamber contained an unidentified insect larva, also an adult (cucujoid?) beetle that was still alive and feebly moving; this beetle could possibly have fallen or walked in during excavation of the nest. (Unfortunately, the residues from Wilson's collections were eventually lost.)

The fourth collection comes from Wau Creek, at about $1200 \mathrm{~m}$ elevation in a "Stage III" [rotten] log (leg. D.H., A.C. and A.H. Kistner, No. 1213); it contained at least 10 workers and a more or less ergatoid queen.

This very distinct species shows some affinities with the tenuis group in the presence of upturned teeth on the labral lobes and lack of median labral tooth, but it is different in its robust build, very prominent foveolate sculpture, shorter mandibles, and the concave anterior face of the first gastric tergum, which gives the name concava. 
Myopias chapmani new species

(Figs. 10, 26)

Diagnosis, worker: A modest-sized member of the tenuis goup; head large, nearly square, with sides almost straight and nearly parallel; posterior margin concave. Eyes small but distinctly facetted. Mandibles rather short and stout; antennal scapes distinctly overreaching posterior border of head. Trunk robust, with broad and deeply impressed metanotal groove; propodeal dorsum less than twice as long as mesonotum. Node of petiole higher and wider than long, convex above. Gaster distinctly constricted between first and second segments. Sculpture predominantly smooth and shining, with spaced, indistinct punctures, especially on head, but sides of propodeum obliquely costulate, subopaque; dorsal propodeal surface finely roughened in part, and bearing a few, coarse, indistinct grooves and punctures, as well as a weak impression just caudad of its midlength. Color light ferruginous red.

Worker, holotype: TL 5.7, HL 1.12, HW 1.07 (CI 96), ML 0.57 (MI 51), MLO 0.87, SL 0.95 (SI 89), EL 0.11, WL 1.77, hind femur L 1.06, hind tibia $\mathrm{L} 1.00 \mathrm{~mm}$.

Worker paratypes ( 21 from type nest series) range downward from the size of the holotype to the smallest individual, which has TL 5.2, HL 1.03, HW 0.98 (CI 95), ML 0.54 (MI 52), MLO 0.81, SL 0.86 (SI 88), EL 0.11, WL 1.63, hind femur L 0.94, hind tibia L $0.86 \mathrm{~mm}$.

Head massive, sides only feebly convex, widest at posterior edge of eyes and tapering almost imperceptibly to rather abruptly rounded posterior corners; posterior border moderately concave across its middle half. Eyes almost round, with about 17 or 18 facets, each situated nearly twice its own diameter away from mandibular insertion; an indistinct groove extends the dorsal (mesal) orbital groove forward onto clypeal wing. Median clypeal lobe slightly longer than wide (CLL 0.14 , CLW $0.13 \mathrm{~mm}$ ), widest near apex, its anterior margin convex and free corners rounded. Median frontal sulcus wide and deep, extending back to posterior third of HL.

Antennal scapes slender, gently bowed, slightly incrassate apicad, overreaching the posterior border of the head by about the same as their apical width when held straight back in dorsal full-face view of head. Funiculus slender, but with an indistinctly 4-merous club; all 
antennomeres longer than wide; funiculus I about twice as long as II.

Mandibles robust, rather short, with a sharp apical tooth and a minute adjacent companion tooth; one subapical and one submedian tooth each isolated, blackened and rounded; basal angle present, but low and rounded. Oblique basal groove and its lateral continuation very distinct. Labral lobes each bearing a delicate, upturned apical tooth, practically impossible to see without dissection. Palpi segmented 3,3; basal maxillary palpomere short and broad, last two subequal in length, but apical broader, fusiform, with apical sensillum; labial palpomeres all slender, the apical slightly longer and thicker than the basal two, and with an apical sensillum.

Trunk robust, divided by a broad and deeply impressed metanotal groove into a promesonotal portion and a shorter propodeal portion. Mesonotum convex, rising above pronotum, sloping caudad, nearly $2 / 3$ as long as propodeal dorsum; propodeum weakly convex, but with a feebly impressed area in the posterior half of its dorsum (variably distinct in paratypes); dorsum rounded unevenly into declivity and with a feeble median impression at the point where they meet; declivity more or less flat, with lateral boundaries distinct, almost submarginate.

Petiolar node distinctly higher than long. its curved dorsal face highest behind the midlength; anterior face in side view straight or feebly concave, sloping caudad; posterior face convex in side view, sloping cephalad. In dorsal view, anterior cornuae of node very prominent; node widest behind, with convex sides, slightly wider than long. Postpetiolar (gastric I) segment slightly broader than long; its anterodorsal border feebly concave in the middle; gastric II a little wider than I, but equal in depth in side view after a distinct constriction between the two that is boldly scrobiculate. Sting long and sharp, gently upcurved (found extended up to $0.60 \mathrm{~mm}$ in various specimens.

Sculpture mainly smooth and shining, with mostly inconspicuous, separated, piligerous punctures, distributed as follows: on dorsum of head, on each side of midline, numerous small ones, averaging about $0.01 \mathrm{~mm}$ in diameter, or smaller, mostly in the space between eye and median sulcus; small punctures distributed sparsely on mandibles, back and sides of head, fore coxae, pronotum, mesonotum, and gastric tergum II. Moderately coarse, often 
elongate, punctures on propodeal dorsum, petiolar node and first gastric tergum. Antennae and legs largely smooth and shining, but with very fine punctulation, increasing toward extremities. Sides of propodeum with fine, partly broken, oblique costulation, rising caudad, surface here subopaque, giving way on dorsal surface to some partial, roughened microsculpture that renders the surface between coarse punctures only weakly shining. Upper propodeal declivity feebly, finely, transversely strigulose, smooth and shining below.

Pilosity consisting of fine, tapered, erect to suberect setae of uneven length, mostly 0.03 to $0.25 \mathrm{~mm}$ long, distributed abundantly over dorsal surfaces of body, venter of head, and gaster, fore coxae, and most surfaces of appendages. Decumbent pubescence is dilute on dorsum of head, directed mesad; more dense on anterior surfaces of mid coxae, and on all tibiae and tarsi.

Color rich, light, ferruginous red; appendages slightly lighter.

Worker variation, apart from the slight mensurable spread, is weak. As already mentioned, the feeble impression, or "saddle," in the posterior dorsal surface of the propodeum varies from distinct to almost absent in different workers.

Queen, dealate: TL 5.2, HL 1.00, HW 1.00 (CI 100), ML 0.55 (MI 55), MLO 0.77, SL 0.84 (SI 84), EL 0.23, WL 1.65, hind tibia L $0.81 \mathrm{~mm}$. Notable for size being slightly smaller than for workers of the same colony. Otherwise, differences are those usual between castes in Ponerini. Nota of pterothorax smooth and shining, with dispersed, small punctures. Propodeum more completely and strongly sculptured than in worker, subopaque, finely transversely strigulose, with a short, longitudinal, median sulcus or impression; lower declivity smooth. Color slightly darker than in worker, especially lightly infuscated parts of cranium, pronotum, median scutum, propodeum, petiole, and first two gastric segments.

Male unknown.

Holotype worker (MCZ) and paratypes (MCZ, BMNH, ANIC) from a small nest in a thick fragment of a rotten branch lying on the ground in wet rain forest along Obi Obi Creek, below and just west of Montville, Blackall Range, Queensland, Australia, 20 May, 1951, leg. Brown. The nest contained 20-30 workers, larvae (since lost together with prey remains), and two dealate queens. The forest at the type locality has since been destroyed (fide P.J. Darlington, 

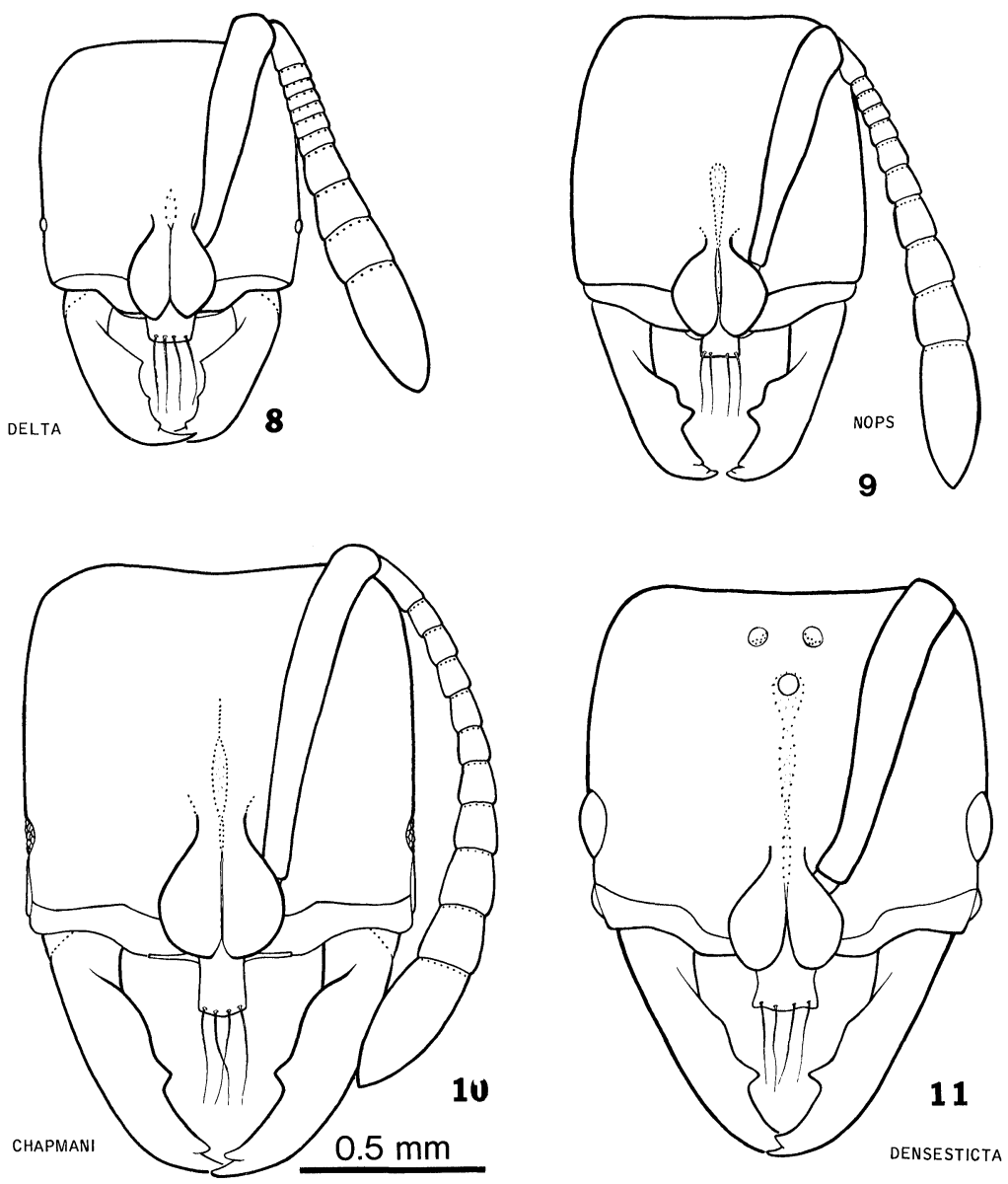

Figs. 8-11, Myopias spp., heads in full-face view, sculpture and pilosity omitted. Fig. 8, M. delta, paratype worker. Fig. 9, M. nops, holotype worker. Fig. 10, M. chapmani, paratype worker. Fig. 11, M. densesticta, paratype queen from Kuranda, Queensland. All to same scale. 
personal communication). The species is named for the late Dr. James W. Chapman, who collected many Myopias series in the Philippines.

\section{Myopias densesticta, new species}

(Figs. 11, 29)

Diagnosis, worker and queen: A member of the $M$. tenuis group, similar to M. chapmani, but with much more distinct and abundant foveolate sculpture and a shorter, wider median clypeal lobe and shorter antennae. Also, the trunk is not deeply divided at the metanotal groove, the petiolar node is more massive, and the gaster is gently tapered, not sharply constricted, behind the first segment.

Worker, holotype: TL 5.6, HL 1.03, HW 0.97 (CI 94), ML 0.55 (MI 53), MLO 0.82, SL 0.85 (SI 88), EL 0.09, WL 1.62, hind femur L 0.87 , hind tibia L $0.83 \mathrm{~mm}$.

Worker, paratypes $(\mathrm{n}=3$ of 9 from two colonies, including largest and smallest, the holotype): TL 5.6-5.7, HL 1.03-1.07, HW 0.97-1.03 (CI 94-97), ML 0.55-0.56 (MI 51-54), MLO 0.82-0.83, SL 0.85-0.86 (SI 83-88), EL 0.09-0.11, WL 1.62-1.71, hind femur L $0.87-0.89$, hind tibia $\mathrm{L} 0.83-0.84 \mathrm{~mm}$.

In overall size, proportions of head, and mandibles, this species is very similar to $M$. chapmani, but the sides of the head are a trifle more convex, and the basal angle of the mandible is a little less distinct; also the following, more definite differences from $M$. chapmani:

(1) Antennae shorter; scapes overreach posterior border when held straight back by only a slight amount, less than their apical width. Segments II through VIII of funiculus wider than long; I (pedicel) more than twice as long as II.

(2) Median clypeal lobe shorter, wider (CLL 0.08-0.10, CLW $0.16-0.17 \mathrm{~mm}$ ), with sharply angular free corners terminating the divergent carinae that form the lateral edges of the lobe.

(3) Promesonotum shorter than propodeum; propodeal dorsum about twice as long as mesonotum, and nearly on the same level; both only weakly convex and meeting at a distinct but not deeply impressed metanotal groove, so that the side-view dorsal profile is a nearly smooth, gently convex outline from top of front pronotal incline to top of propodeal declivity.

(4) Petiolar node more massive and more nearly cuboidal, less no- 
tably longer than high; seen from above wider than long, but sides convex; widest near midlength.

(5) Second gastric (true abdominal IV) segment narrower and lower than first segment (postpetiole), so that the gaster is gradually tapered caudad of I, and not constricted and recovering after.

(6) Body, especially head, trunk and petiolar node, with deeper and much more distinctly developed foveolate sculpture, the punctures mostly $0.01-0.02 \mathrm{~mm}$ in diameter and densely crowded, contiguous on front of head between eyes and frontal lobes, becoming larger, mostly $0.02-0.03 \mathrm{~mm}$ in diameter and narrowly separated on posterior half of head, at times with intervening, indistinct, longitudinal strigulosity, and still coarser and more widely spaced on sides and underside of head and near median frontal sulcus (which reaches back to near the posterior quarter of HL). Trunk and petiole with abundant foveolae, mostly $0.02-0.04 \mathrm{~mm}$ in diameter, separated on the average by a little more than their own diameters, but more crowded and more elongate on sublateral strips of propodeal dorsum; truncal midline strip partly open, with few foveolae. In general, interfoveolar surfaces smooth and shining, but lower sides of propodeum indistinctly, longitudinally costulate, and sides of petiolar node coarsely and densely foveolate and minutely roughened, more or less opaque. Gaster I smooth, with scattered coarse punctures, and these become fewer and smaller still on gaster II. Mandibles smooth and shining, with scattered punctures. Antennal scapes and legs smooth and shining, but with fine punctulation. Propodeal declivity nearly smooth, but peppered with many small foveolae. Clypeus smooth and shining.

(7) Pilosity and pubescence more abundant than in $M$. chapmani, most notably on mandibles and antennal scapes; decumbent pubescence on head more conspicuous, directed mesad.

(8) Color perhaps averaging slightly darker than in M. chapmani, but legs and antennae tending to be lighter, more yellowish red. As in chapmani, the palpi are segmented 3,3, and upturned teeth are present, one on each labral lobe. Worker variation is very slight overall. The Koombooloomba series averages very slightly larger, and the compound eyes may be a trifle larger than in the Shipton's Flat colony.

Queen, dealate, a unique taken in rotten wood in a rain forest patch near Kuranda, Queensland, 31 October 1950, leg. Brown: TL 
6.7, HL 1.07, HW 1.05 (CI 98), ML 0.52 (MI 49), MLO 0.81, SL 0.85 (SI 81), EL 0.24, WL $1.92 \mathrm{~mm}$.

Male unknown.

Holotype [MCZ] one of six workers from Shipton's Flat, south of Cooktown, Queensland, during June 1958, leg. P.F. and P.J. Darlington. This locality is savannah woodland grading into riparian rain forest (gallery forest), and lies at an elevation of about $300 \mathrm{~m}$. (The Kuranda queen is from a similar elevation.) A pin of three workers comes from Koombooloomba, near the dam of the same name south of Ravenshoe, Queensland, at about $750 \mathrm{~m}$ in rain forest, "4/7/71," leg. Taylor and J. Feehan. We have no information about possible prey.

The name densesticta refers to the characteristic foveolate sculpture.

\section{Myopias tasmaniensis}

(Fig. 16)

Myopias tasmaniensis Wheeler, 1923, Psyche 30:177-179, fig. 1, worker. Type loc: Hobart, Tasmania.

Trapeziopelta tasmaniensis: Brown, 1953, Psyche 60:51, records from Dandenong Range, Victoria, Australia.

Trapeziopelta diadela Clark, 1934: Mem. Nat. Mus., Melbourne, Australia, 8:54-55, pl. 4, f., 7,8, worker, queen. Type loc., Turton's Track, Otway Ranges, Victoria. (Syn. by Brown, 1953).

Two collections made by Father Bede Lowery extend the range far to the north in eastern Australia; Minnamurra Falls, near Kiama, New South Wales, nest in soil of very moist forest, behind rock slab set in a vertical bank, 22 Dec. 1959; Cunningham's Gap, southeastern Queensland, at about $600 \mathrm{~m}$ in rain forest,. $22 \mathrm{Jan}$. 1961.

\section{Myopias tenuis new combination}

(Figs. 15, 17)

Trapeziopelta tenuis Emery, 1900, Természetr. Füz. 23:313-314, dealate queen. Type loc.: Beliao Island, near Berlinhafen (now Aitape), Papua New Guinea. 1902, 155, worker, Sattelberg, Huon Peninsula, Papua New Guinea.

Trapeziopelta tenuis var. fulvescens Emery, 1902:155, worker, dealate queen. Type loc.: Sattelberg, Huon Peninsula, Papua New Guinea. New synonym.

This is the smallest of the known Melanesian Myopias species, and also the most common and widespread. The typical form is 

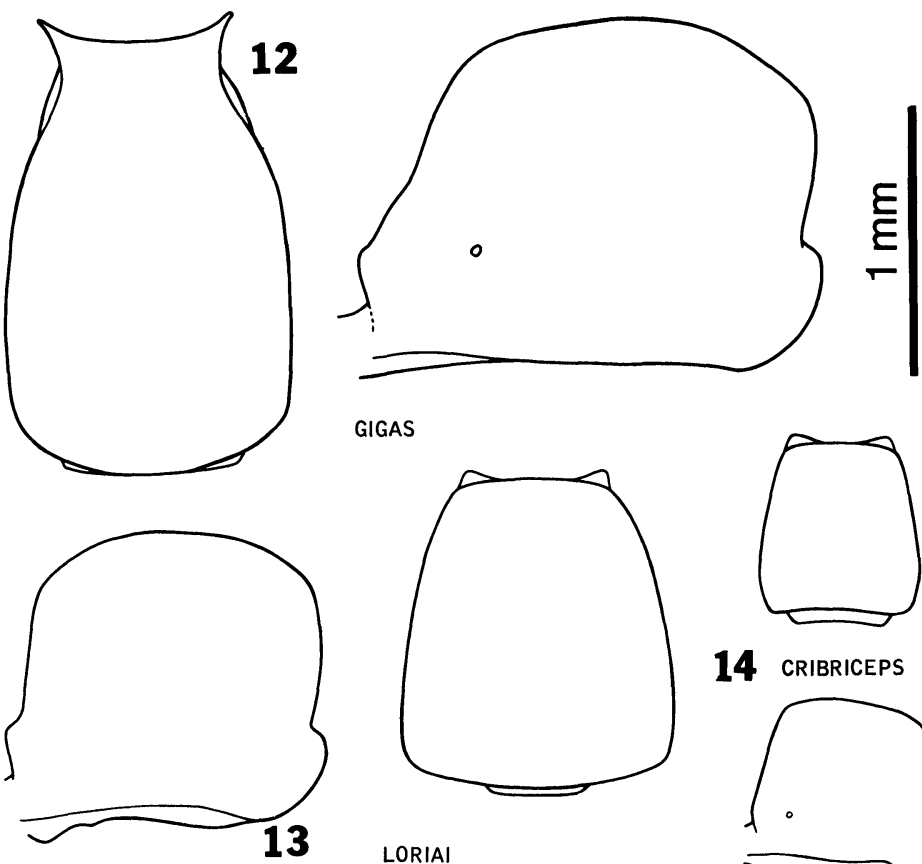

GIGAS

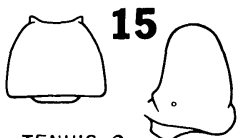

TENUIS 우

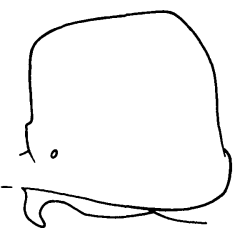

18

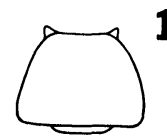

TASMANIENSIS

16

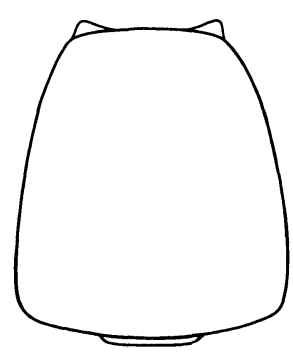

LORIAI

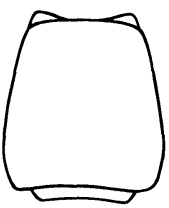

14 CRIBRICEPS
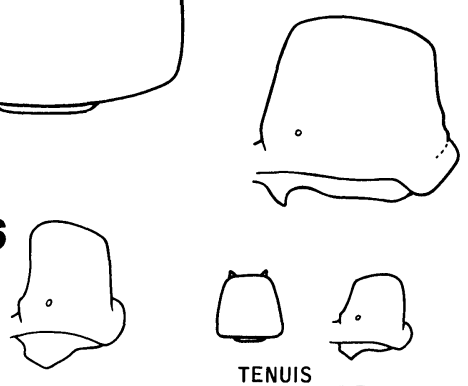

17

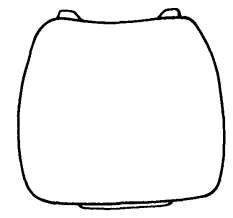

CONCAVA

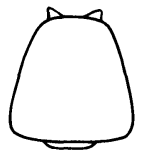

LEVIGATA

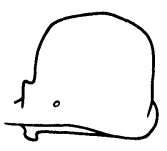

19

Figs. 12-19, Myopias spp., petiolar nodes in lateral and dorsal view, sculpture and pilosity omitted, all to same scale. Fig. 12, M. gigas holotype worker. Fig. 13, M. loriai worker fro Gemeheng, Huon Peninsula, Papua New Guinea. Fig. 14, $M$. cribriceps worker from Bubia, near Lae, Papua New Guinea. Fig. 15, M. tenuis queen from Bubia, near Lae, Papua New Guinea. Fig. 16, M. tasmaniensis from Olinda, Victoria, Australia. Fig. 17, M. tenuis worker from Bubia, near Lae, Papua New Guinea. Fig. 18, M. concava paratype worker from lower Busu R., near Lae, Papua New Guinea. Fig. 19, M. levigata worker from Nganduo, Huon Peninsula, Papua New Guinea. 
small, has slightly convex sides of the head, scapes that just fail to reach (or just barely reach) the occipital border when held straight back, and a median clypeal lobe that is as long as, or slightly longer than, wide at its widest (near apex). The end of the lobe is convex or straight, and the free angles may be rectangular or rounded. Measurements for Papua New Guinea North Coast workers are: TL 2.8-3.7, HL 0.53-0.71, HW 0.45-0.60 (CI 81-91), ML 0.30-0.43 (MI 81-92), MLO 0.40-0.57, SL 0.42-0.58 (SI 87-95), EL 0.03-0.06, WL $0.95-1.25 \mathrm{~mm}$. Workers of a colony series from Salawati Island, at the western end of New Guinea, fall within these dimensions and proportions. Workers from Bisianumu, in the hills above Port Moresby, fit the North Coast dimension range, while a sample from Karema, in the lowlands north of Moresby, tends slightly to exceed the North Coast samples in size.

Samples from the Cape York area of North Queensland average larger than any of the New Guinea series; a large worker from the Black Mt. Road, north of Kuranda, measures TL 4.1, HL 0.74, HW 0.67 (CI 91), ML 0.43 (MI 91), MLO 0.58, SL 0.59 (SI 88), EL 0.04, WL $1.34 \mathrm{~mm}$. The Australian samples often have the laid-back scapes reaching the posterior border of the head, and the posterior border is more distinctly concave. In addition, the median clypeal lobe tends to be wider, often as wide as or wider than long, and the minute punctures, especially on the head, are a trifle coarser and more distinct. Several of these series have sordid yellowish individuals, undoubtedly partly callow, that correspond to var. fulvescens.

New locality records: PAPUA NEW GUINEA: Karema, Brown R., rotten $\log$, lowland rain forest, leg. Wilson, No. 552. Bisianumu, near Sogeri, about $500 \mathrm{~m}$, hill rain forest, Wilson Nos. 637, 637A, litter and rotten wood, strays. In the vicinity of Lae (Didiman Creek, Bubia and lower Busu R.), several nests and litter strays, Wilson Nos. 688, 689A, 690, 716, 939, 962, 978, 1037, 1045, 1058, all in lowland rain forest. No. 689 was a small colony in a Zorapterastage $\log$, with about ten workers and two queens. No. 716 was a worker carrying an entomobryid collembolan about its own length lengthwise beneath its body, army ant fashion. No. 1037 was a nest in a cavity in the under surface of a hard, barkless log in leaf litter. No. 1045, a nest in a soft Passalus-stage log, had peripheral galleries packed with unidentified arthropodan cuticular fragments. Nadzab, dry evergreen forest, Wilson No. 1100. Wau north, on Bulolo road, 
$650 \mathrm{~m}$, leg. S. Peck, B-278. IRIAN JAYA: near Phillips Petroleum Base Camp, SE Salawati I. (just off western extremity of Vogelkop), swamp forest near sea level, leg. Brown No. 81-189, nest in rotten wood, with at least 15 workers, a dealate queen, a male, about a dozen pupae in tan cocoons, and a few half-grown larvae. AUSTRALIA, N. QUEENSLAND: Black Mt. road N. of Kuranda, 300-600 m, leg. P.F. Darlington, in rain forest, small colony with at least two dealate queens. Mt. Cudmore Range, $11 \mathrm{mi}$. N. of Ingham, about $210 \mathrm{~m}$, six workers from rotten log in small roadside patch of disturbed rain forest, leg. Taylor, Acc. No. 1706. Mulgrave Forestry Road, $17^{\circ} 18^{\prime} \mathrm{S}, 145^{\circ} 48^{\prime} \mathrm{E}$, leg. Ward No. 4366 , from rotting epiphyte fern on rain forest floor.

From the SOLOMON ISLANDS we have three scanty samples of forms sent from ANIC that could belong to M. tenuis, or to sibling species:

(1) A large form, extending some of the tendencies seen in Australian series; HW 0.80, EL $0.09 \mathrm{~mm}$; scapes reaching posterior border of head. Propodeal dorsal profile a little more convex than usual in M. tenuis. Color castaneous. Two workers from Guadalcanal I.: Mt. Austen, Feb. 1966, leg. P.M. Greenslade, No. 21095.

(2) A small worker, also from Mt. Austen, Guadalcanal, 14/5/1963, leg. P.M. Greenslade, No. 6076; HW 0.55, EL 0.03 mm; scapes very short, failing to reach posterior border of head by at least the apical scape width; posterior border of head weakly concave. Color yellowish brown. Sides of head straighter and more parallel-sided than in the other Mt. Austen sample.

(3) A worker from San Cristoval I., Humi R. est., N.E. Wainoni, leg. Royal Society Expedition, 1966-1, HW 0.60, EL 0.05 mm; sides of head almost perfectly straight and parallel, posterior border feebly convex; scape fails to reach posterior border of head by about half of apical scape width; mandibles unusually short (ML 0.37 , MLO $0.47 \mathrm{~mm}$ ) and broad; basal angle forming a distinct convexity. Color deep brownish red.

I suspect that the Solomons will eventually yield much more variation in the tenuis complex; the available material is simply inadequate as a basis for understanding the complex in this archipelago. 
Key to Known Myopias Species of Australia, Based on Workers

1. Small, slender species ( $\mathrm{HW}<0.75 \mathrm{~mm}$ ); worker compound eye reduced to a single smoothly lenticular dot $<0.05 \mathrm{~mm}$ long (in Australia, N. Queensland) .................. tenuis More robust species (HW $>0.75 \mathrm{~mm}$ ); worker compound eye 0.05 or more long, with 3-5 rows of distinct, raised ommatidia (Figs. 10,11).............................

2. Second gastric segment lower and narrower than the first and tapering gently apicad, not constricted at base (N. Queensland) densesticta

Second gastric segment wider than the first and sharply constricted from its own acrotergite basad.................

3. Antennae shorter, scapes not overreaching posterior border of head when they are held straight back from insertions as head is viewed full-face; small funicular segments (funiculus II-VII at least) broader than long (Tasmania to SE Queensland) ....... tasmaniensis Antennae longer, scapes distinctly overreaching posterior border in full-face view of head; all antennal segments longer than broad, or at least as long as broad ................. (S. Queensland: Blackall Range) .............. chapmani

\section{Myopias ruthae new species}

(Figs. 7, 20)

Diagnosis, worker: A modest-sized Myopias; head longer than broad, with nearly parallel but gently convex sides and weakly convex posterior border; scapes curved, barely surpassing posterior border; funicular club indistinctly 6-merous. Median frontal groove deep and wide, reaching to the posterior quarter of head length. Median clypeal lobe broad, short, rectangular, widest basad. Labrum without a median tubercle. Eyes fairly large, convex, finely facetted. Mandibles robust, gently curved, with 4 teeth and a low basal angle. Body robust, metanotal groove distinct but weakly impressed. Petiolar node massive, subcuboidal; gaster short and thick. Sculpture of numerous coarse punctures or foveolae, dense and contiguous, or nearly so on most of head and sides of petiolar node; foveolae sparser mesad on vertex, trunk and succeeding terga, 
the surface here prevailingly smooth and shining. Color piceous, nearly black, with contrasting tan appendages.

Worker, holotype: TL 5.2, HL 0.96, HW 0.86 (CI 90), ML 0.48 (MI 50), SL 0.73 (SI 85), EL 0.14, WL 1.60, hind femur L 0.80, hind tibia L $0.83 \mathrm{~mm}$.

Description mainly directed at details not fully covered in the diagnosis and figures. Antennal scape broadly curved in basal half, incrassate distad; apical width about $0.12 \mathrm{~mm}$, or slightly less than maximum eye length. Funicular segment $I$ about twice the length of II. Eye with distinct but fine ommatidia, numbering about 11 or 12 units in the longest diagonal row, darkly pigmented. Median clypeal lobe about $0.05 \mathrm{~mm}$ long (CLL) and about 0.14 wide (CLW) at apex, about $0.15 \mathrm{~mm}$ wide at base where it meets frontal lobes; anterior border straight, free corners subrectangular. In examining the single, intact specimen, no upturned teeth could be seen at the apex of each labral lobe, but a dissection would be needed to make sure that they are really absent. Mandibular armament consists of an acute apical tooth and a small adjacent tooth, then after a gap another large, blunt tooth, another gap and a similar-sized but more acute median tooth, then halfway from this to the base, a low, rounded basal angle. Oblique groove (strix) near dorsal base of mandible distinct, continuing along lateral margin to near apex. MLO $0.77 \mathrm{~mm}$.

Trunk robust, dorsal outline in side view nearly straight, the mesonotum feebly sunken; metanotal groove slightly impressed, but distinct; propodeal dorsum very feebly convex, rounding obtusely into declivity, but sides of declivity forming blunt angles with pleural faces of trunk. Propodeal spiracle small and round, situated at mid height. Petiolar node massive, subcuboidal, slightly wider behind than long; slightly higher than long if one ignores the small, hooklike anterior subpetiolar process; dorsal surface convex in both directions.

First gastric (postpetiolar) segment higher and wider (by about 4:3) than long. Succeeding (gastric II) segment about as wide as the first, and only slightly longer, but slightly thinner dorsoventrally. Sting long and slender, gently upcurved.

Sculpture distinctive, consisting basically of a smooth, shining integument invaded by coarse, mostly umbilicate, piligerous foveolae. The foveolae are densest and smallest $(0.02-0.03 \mathrm{~mm}$ diameter) 

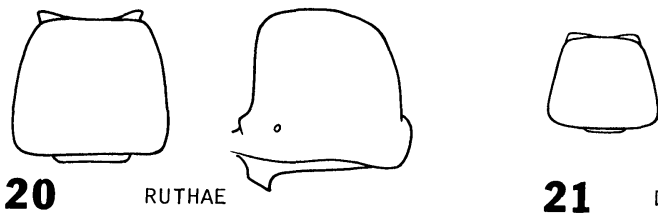

21 DELTA
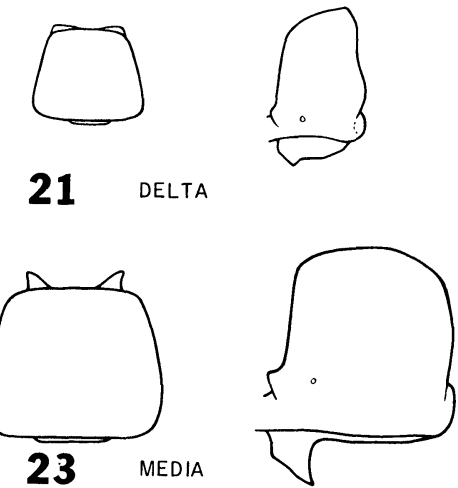

22 JULIVORA
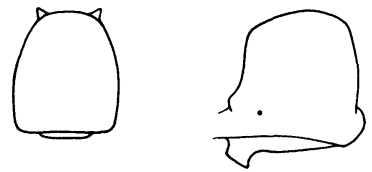

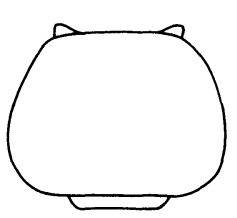

24 LATINODA ?
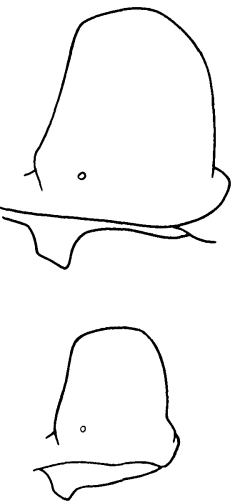

26 CHAPMANI

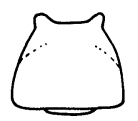

NOPS

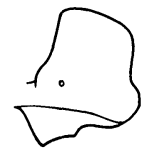

$1 \mathrm{~mm}$
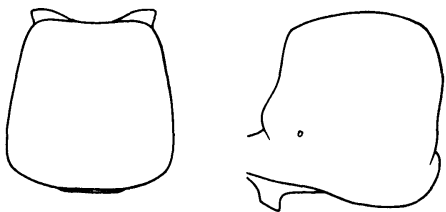

25 LOBOSA
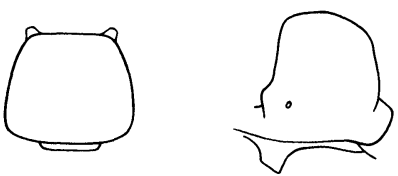

27 LATINODA
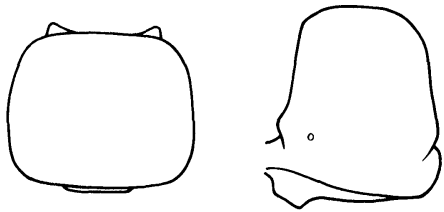

29 DENSESTICTA \&

Figs. 20-29, Myopias spp., petiolar nodes in lateral and dorsal view, sculpture and pilosity omitted, all to same scale. Fig. 20, M. ruthae holotype worker. Fig. 21, $M$. delta, paratype worker. Fig. 22, M. julivora, paratype worker from Papua New Guinea. Fig. 23, M. media, holotype worker. Fig. 24, M. latinoda queen from Maffin Bay, Irian Jaya. Fig. 25, M. lobosa, paratype worker. Fig. 26, M. chapmani, paratype worker. Fig. 27, M. latinoda worker from Maffin Bay, Irian Jaya. Fig. 28, $M$. nops, holotype worker. Fig. 29, M. densesticta paratype queen from Kuranda, Queensland. 
on anterior and sides of head, where most are contiguous and yield a reticulate-foveolate surface that is subopaque in most lights. This kind of sculpture, a bit more loosely distributed, covers the upper sides and dorsum of trunk and petiole, except for median posterior part of vertex, midline of trunk, and dorsal midline of petiole, which have wide spaces free of most foveolae, and are smooth, shining. Sides of trunk below largely smooth, with sparse foveolae, and posteriorly, low down, with a few fine, longitudinal costulae. Sides of petiolar node foveolate-striate. Gaster with spaced foveolae, becoming smaller $(0.02 \mathrm{~mm})$ and sparser caudad, interspaces smooth and shining, but a double band of foveolae along apical margin of second gastric tergum. Mandibles and legs with sparse punctures, generally otherwise smooth and shining; scapes and middle tibiae, and all tarsi, more densely punctulate, but still shining.

Hairs numerous, fine, tapered, suberect to decumbent, mostly 0.04 to $0.25 \mathrm{~mm}$ long; those on head and appendages mostly short, while those on clypeal lobe, trunk, petiole, and especially gastric apex are longer.

The species is named for Dr. Ruth Lippitt Willey.

Holotype (MCZ) a unique worker specimen from Bubia, about 13 $\mathrm{km} \mathrm{NW}$ of Lae, Papua New Guinea, about $20 \mathrm{~m}$ above sea level, in high-graded rainforest, 26 March 1955, by E.O. Wilson (MCZ). The worker was foraging under the bark of a large Zoraptera-stage (rotting) $\log$.

This species is distinct from all congeners, but difficult to place to a group. Probably it comes closest to the tenuis group than any other so far described, but the longish head, bulging eyes, short scapes and coarsely foveolate sculpture will distinguish it from all tenuis-group species.

\section{Myopias lobosa new species}

(Figs. 2, 3, 25)

Diagnosis, worker and queen: Head distinctly longer than broad; median clypeal process obsolete; labrum without median tubercle. Mandibles much broadened, each with the two major teeth before the apex exaggerated into triangular lobes; blades of mandibles sharply curved ventrad and rotated so that their blades lie nearly parallel to the sagittal plane of the head at full closure. Antennal 
scapes very short. Sculpture composed of distinct punctures, fine and densely arranged on cephalic dorsum, with smooth to finely shagreened interspaces.

Worker, holotype and six paratypes from type nest series: TL 6.0-6.3, HL 1.27-1.31, HW 0.98-1.04 (CI 76-82), ML 0.76-0.78 (MI 75-83), SL 0.74-0.77 (SI 75-80), EL 0.22-0.25, WL 2.01-2.09 $\mathrm{mm}$.

Head with gently convex subparallel sides, straight to feebly convex occipital border, and broadly rounded posterior angles. Greatest head width slightly behind midlength. Eyes oval, only feebly convex, their greatest diameter greather than maximum width of scape; about $12-15$ fine facets in rows across the short axis; eye separated from anterior corner of head by about $2 / 3$ its own length or slightly more. Frontal sulcus extends slightly beyond midlength of head. Median clypeal process obsolete, represented only by a weak convexity between the frontal lobes with two or three minute piligerous tubercles. Form of mandibles shown in Figs. 2, 3. Scapes reaching roughly to about $3 / 4$ the distance between their insertions and the occipital border; segment $I$ of funiculus distinctly longer than II; II through X increasing rather uniformly in size, so that no club is formed.

Trunk as seen from side forming gentle, subequal promesonotal and propodeal convexities, separated by the impressed metanotal groove. Petiolar node slightly higher than long seen from the side (without subpetiolar process) and very slightly longer than broad seen from above. Postpetiolar segment seen from above about 4/5 as long as broad, slightly shorter than the succeeding segment.

Dorsum of head densely sown with fine, uneven-sized punctures, close together, but interspaces mostly smooth and shining; region posteromesad of compound eyes with densest punctation. Sides and underside of head smooth and shining and with scattered coarse punctures. Mandibles, gastric apex, scapes and legs smooth and shining.

Trunk, petiole, and first two gastric segments with numerous coarse, mostly elongate piligerous punctures. Between punctures the integument is mostly smooth to shagreened on the dorsum, becoming striolate and subopaque on sides and rear of trunk and petiolar node, and to some extent on mesonotum and propodeal dorsum.

Pilosity of fine, tapered, erect hairs, moderate in length and generally distributed. Head with abundant, mesally directed decumbent 
pubescence over most of the dorsum; scapes and legs with similar pubescence, directed apicad. Color bright to deep brownish-red; mandibles and appendages lighter, more yellowish.

Holotype (MCZ) a worker from a uninidal series of 7 workers and a queen from the Cuernos Mts., near Dumaguete, Negros, Philippine Islands (Chapman). Paratype workers from the same colony (MCZ, BMNH).

Queen, dealate: slightly larger than the worker. Flight sclerites and wing stumps well developed. Petiolar nodes slightly broader than long as seen from above. Mesonotum and propodeum shagreened (finely reticulate) above and with scattered coarse punctures. Ocelli small. Compound eyes large; maximum diameter ca. $1 / 5$ the full head length (HL).

\section{Myopias nops new species}

(Figs. 9, 28)

Diagnosis, worker: A modest-sized, depigmented (dull yellowish) species without eyes; sculpture opaque, predominantly densely reticulate-punctulate over head, trunk, node and first gastric segment. Mandibles short and stout, with basal angle distinct, but rounded and close to submedian tooth. Median clypeal lobe distinct, short with subacute free corners and indented apical margin. Antennal scapes just reaching posterior border of head. Petiolar node thick, but tapered apicad, its sternal keel ending behind in an abrupt angle, paired bilaterally as in Ponera.

Worker, holotype: TL 4.4, HL 0.85, HW 0.77 (CI 91), ML 0.42 (MI 49), MLO 0.59, SL 0.65 (SI 84), WL 1.30, petiole L 0.45, hind femur L 0.65 , hind tibia L $0.64 \mathrm{~mm}$.

The two paratype workers, both dismembered, hardly differ from the holotype by more than the usual error of measurement in the standard dimensions. Since the three specimens of the type series are all incomplete (one lacking head, another without gaster, various legs missing, sculpture in part obscured on holotype), the description is composite.

Head oblong with nearly parallel, weakly convex sides, greatest width a little way anterior to midlength; posterior corners rounded; posterior border straight in full-face view, or perhaps just the slightest bit concave. Median frontal sulcus broad but short, not reaching back to mid-HL. Eyes obsolete, or at least unpigmented and not 
distinguishable amid the sculpture in strong light at 50X. Antennae with robust scapes that just reach the posterior border of the head when held straight back; funiculus long, with an indistinctly 4merous apical club; funicular segments II through $\mathrm{V}$ short, wider than long; pedicel (I) is $3-4 \times$ as long as II; VI-XI longer than wide.

Mandibles short and stout, strongly downcurved, with acute apical tooth and blunt companion tooth, followed after long gaps by two blunt teeth, of which the submedian is followed closely basad by a distinct but rounded basal angle. Labrum without a distinct median tooth, but the two lobes each bear a delicate, upturned tooth at apex. Palpal segmentation not determined. Median clypeal lobe distinct but short, CLL 0.08, CLW 0.12, with indented or concave apical margin and subacute free corners; one side deformed in holotype.

Trunk compact, with a weakly convex dorsal outline (in side view) between steeply sloping pronotal and propodeal declivities; promesonotum distinctly longer than propodeum; mesonotum weakly convex; metanotal groove strong, but only moderately impressed; propodeal dorsum feebly convex overall, but with a very shallow impression near midlength. Position of metapleural suture indicated by a vague sulcus. Propodeal declivity rather abruptly rounded off from dorsum, weakly transversely aciculate above, smooth and shining below, meeting sides of propodeum through bluntly subrectangular curves. Lengths of propodeal dorsum: mesonotum about as 5:3.

Petiolar node thick but higher and broader than long; summit anterior, dorsal face rounded, but meeting steep concave anterior face through an abrupt curve, rounding broadly caudad into posterior face, which is low, flat and smooth. Ventral keel of petiole with a large, obliquely truncate process in front and another, lower, rectangular or obtuse angle farther caudad; this last angle is paired bilaterally with a mate, and together they appear to be homologous with the similar teeth or angles diagnostic of the genus Ponera.

Gaster robust; constriction behind first segment deep, broad, scrobiculate. First segment abruptly truncate in front, the front face vertical, flat, smooth and shining; second subequal in length to first, but slightly wider than first.

Head, trunk, and anterior disc of first gastric segment densely reticulate-punctulate and opaque, with a minutely pitted overlay; 
sides of trunk, especially mesopleura and metapleura, and sides of node, obscurely striate-punctulate; coxae minutely striate, becoming smooth anteroventrad. Posterior disc of gastric tergum I, and most of II, densely covered with small, round punctures with smooth, shining, but very narrow interspaces, becoming wider behind; undersides of the same two gastric segments with scattered coarse punctures, the interspaces in part minutely roughened (I) or shining. In addition to the other surfaces listed above as smooth and shining may be added the gastric apex, mandibles and femora, all with scattered punctures. Antennae, tibiae, tarsi mostly finely punctulate, but more or less shining.

Pilosity reduced to a mostly pubescence-like vestiture, abundant but not very conspicuous, of appressed to subdecumbent, fine hairs; only the clypeal and paired humeral setae as long as $0.10 \mathrm{~mm}$, but the specimens are badly rubbed, and probably had moderately, abundant, but still fine and short, erect and suberect pilosity, some of which can still be seen at times on scapes, legs, and dorsum of trunk, as well as gastric apex.

Color dull, light brownish yellow.

Queen and male unknown.

Holotype (MCZ) and two paratypes workers (MCZ, BMNH) from Taiwan: Rarasan (probably the same as the mountain now called La La Shan, $24^{\circ} 44^{\prime} \mathrm{N}, 121^{\circ} 26^{\prime} \mathrm{E}$, to the southwest of T'ai Pei), 31 July 1933, leg. R. Takahashi. I have no information concerning the habitat, nest site, or prey. This is obviously a cryptic-foraging form, probably living in the soil or in rotten wood. A related undescribed species has been found in Borneo.

The type series was originally three workers mounted on points on a single pin; these were heavily damaged in a laboratory accident, but the species is so interesting that we decided to describe it from the collectively adequate remains. The name nops is from a Greek word meaning blind.

\section{Myopias delta new species}

(Figs. 8, 21)

Diagnosis, worker and queen: A modest-sized species, completely distinct from all congeners in possessing downcurved triangular mandibles with distinct basal and masticatory borders meeting at a dentiform basal angle. Head oblong, with convex sides and straight 
posterior border, and broadly rounded posterior corners. Worker eyes reduced to dots. Frontal lobes and median clypeal lobe large; clypeal lobe squarely truncate. Antennae very robust; scapes overreaching posterior border of head; funiculus dominated by a long, thick, 4-merous apical club. Trunk compact, weakly convex, separated into two subequal parts by a distinct but not sunken metanotal groove. Petiolar node short and high, summit posterior and acutely rounded, posterior face vertical and feebly concave. Gaster constricted behind first segment. Integument smooth and shining, with separated minute punctures. Color dark yellowish brown.

Worker, holotype: TL 4.1, HL 0.79, HW 0.70 (CI 89), ML 0.30 (MI 38), MLO 0.54, SL 0.66 (SI 94), EL 0.04, WL 1.27, hind femur L 0.68 , hind tibia $\mathrm{L} 0.61 \mathrm{~mm}$.

Worker paratypes (15 from type nest series) range downward from size of holotype to smallest individual, TL 3.9, HL 0.75, HW 0.68 (CI 91), ML 0.29 (MI 39), MLO 0.49, SL 0.62 (SI 91), EL 0.04, WL $1.20 \mathrm{~mm}$.

Head a little longer than broad, with parallel gently convex sides, straight posterior border, and rounded posterior corners. Frontal lobes broad, median clypeal lobe thick and wide (CLL 0.07, CLW $0.14)$, squarely truncate at apex, sides slightly convergent towards apex. Median frontal sulcus very short, not extending rearward past constricted ends of frontal carinae.

Mandibles basically of the ordinary ponerine, rather than Myopiaslike, form, triangular and strongly downcurved, with distinct basal and oblique masticatory margins, each furnished with five coarse, spaced teeth, the most basal of which, corresponding to the basal angle, is subacutely dentiform; apical tooth the largest and most acute; masticatory margins crossing over one another at full closure. Basal oblique groove and its lateral extension (strix) strongly developed.

Eyes small, round and dot-like, with indistinct facets, only 0.03-0.04 $\mathrm{mm}$ long, and distant from mandibular insertions by about $0.20 \mathrm{~mm}$. Antenna massive, scape thick, especially toward apex, and overreaching posterior border of head (when held straight back in full-face view) by more than half apical scape width; funiculus with 4-merous club (which takes up more than 0.6 of funicular length) following six short, transverse ring segments (II through VII); pedicel (funiculus I) about $5 \times$ length of II. 
Labrum without a median tooth, but each of its two lobes bears a delicate, upturned apical tooth. Palpi segmented 3,3.

Trunk compact; aside from the rounded declivities of pronotum and propodeum, the dorsal profile in side view is only weakly convex, with moderate interruptions at premesonotal suture (movable) and metanotal groove; latter is moderately wide and distinctly, but not very strongly, impressed, and it divides the trunk into approximately equal anterior (promesonotal) and posterior (propodeal) halves. Dorsum of propodeum gently convex, about twice as long as mesonotum; declivity of propodeum steeply sloping, its outline convex in side view, but the surface feebly concave, and weakly submarginate above and laterally, as seen from above.

Petiolar node short and high, highest and widest behind at narrowly rounded summit, after which the posterior face drops off sharply and almost vertically. Anterior face nearly as steeply sloping upward, shorter, meeting sloping dorsal face at an obtusely rounded angle. Sternal keel prominent, with a thick, obliquely truncate anterior process, pointed behind, then diminishing convexly caudad (see fig. 21). In holotype and two of the paratypes, the posterior convex portion bears an additional low point or tubercle, but shape of keel is variable in any case.

Gaster robust, distinctly constricted after first segment; segment II about as high as I, and only very slightly wider. Sting long, sharp, upcurved, capable of at least $0.4 \mathrm{~mm}$ extension. Seen from above, anterior border of gaster I transverse, straight.

Body smooth and polished, with well-spaced, small (mostly 0.01 $\mathrm{mm}$ diameter or less), piligerous punctures, most numerous on dorsum of head and gaster. Antennae, frontal lobes, tibiae and tarsi densely and finely punctulate. Bullae of metapleural glands obscurely striate.

Longer pilosity abundant on body, sparse on antennae and mandibles, and almost lacking on legs; mostly 0.03 to about $0.20 \mathrm{~mm}$ long, appressed to erect, but mainly decumbent to suberect on propodeum, node, and first two gastric segments; longest on clypeal lobe, propodeum, node and gastric apex. Pubescence mostly appressed to decumbent, inconspicuous and mesally inclined on anterior half of head, more abundant and conspicuous on antennae and legs.

Color dark yellowish brown or orange brown; legs, mandibles, antennal scapes slightly more yellowish. 
Queen, dealate, from holotype nest series: TL 4.7, HL 0.80, HW 0.71 (CI 89), ML 0.34 (MI 43), MLO 0.57, SL 0.70 (SI 99), EL 0.18, WL $1.47 \mathrm{~mm}$.

Showing the usual ponerine differences of caste, and darker, deep brownish red, in color; scutum yellowish brown, with a broad, V-or $\mathrm{Y}$-shaped median fascia of deep reddish brown; mandibles, antennae, legs, and indefinite patches on lateral areas of pronotum and upper mesopleura obscure yellowish brown. Punctures a little coarser and more conspicuous than in workers. An additional dealate queen apparently belonging to this species, taken in 1901 by $\mathrm{L}$. Biró (Hungarian Natural History Museum), comes from FriedrichWilhelmshafen (now Madang, Papua New Guinea); it is notably smaller (HL 0.62, HW $0.50 \mathrm{~mm}$.) than either workers or queen from the type colony; and was found in the Hungarian collection placed with the $M$. tenuis.

Holotype (MCZ) and paratypes (MCZ, BMNH, ANIC) from a colony collected in rain forest just west of the lower Busu River, near Lae, Papua New Guinea on 9 May 1955, by Wilson (No. 983). Wilson's notes on this colony are slightly modified:

"A colony of one queen and about 30 workers, with brood at all stages, none preponderant; in a crumbling small Passalus-stage log, diameter about 5 inches, held in shape by intact bark. Ants relatively fast, nervous, similar to other [Myopias] species. Workers and brood scattered through a number of indistinct galleries and chambers in the crumbling wood. In one chamber near larvae was a fresh, decapitated worker of a small Leptogenys species. Around another, large chamber was the kitchen midden, consisting of discarded [Myopias] cocoons and numerous remains of ants, mostly or entirely myrmicines, including at least two genera (q.v.)." The "q.v." refers to the vial containing the whole colony. Unfortunately, the Myopias brood and the midden remains, left in alcohol after an adult sample had been mounted from the vial, was lost in transit by a colleague who had borrowed Wilson's and Brown's Myopias collection residues for study.

From the circumstances of the collection as noted by Wilson, it seems likely that $M$. delta is an ant predator specializing on Myrmicinae, but perhaps occasionally accepting ponerines or other subfamilies. We need further collections and field and laboratory 
observations to confirm this interesting possibility and to learn the details of the $M$. delta behavior and ecology.

The name delta refers to the triangular mandibles. This species cannot easily be placed to species group, and the mandibular form even puts generic assignment into doubt. The 3-merous palpi (both sets) and the upturned tooth on each labral lobe probably are derived characters shared with the tenuis group, so the triangular mandibular shape may well be secondarily derived from the Myopias plan; it seems, indeed, that the dentition of $M$. delta is more easily homologized with that of various Myopias species than it is with the run of Pachycondyla groups. It thus becomes doubly important to find again the larvae of $M$. delta. 

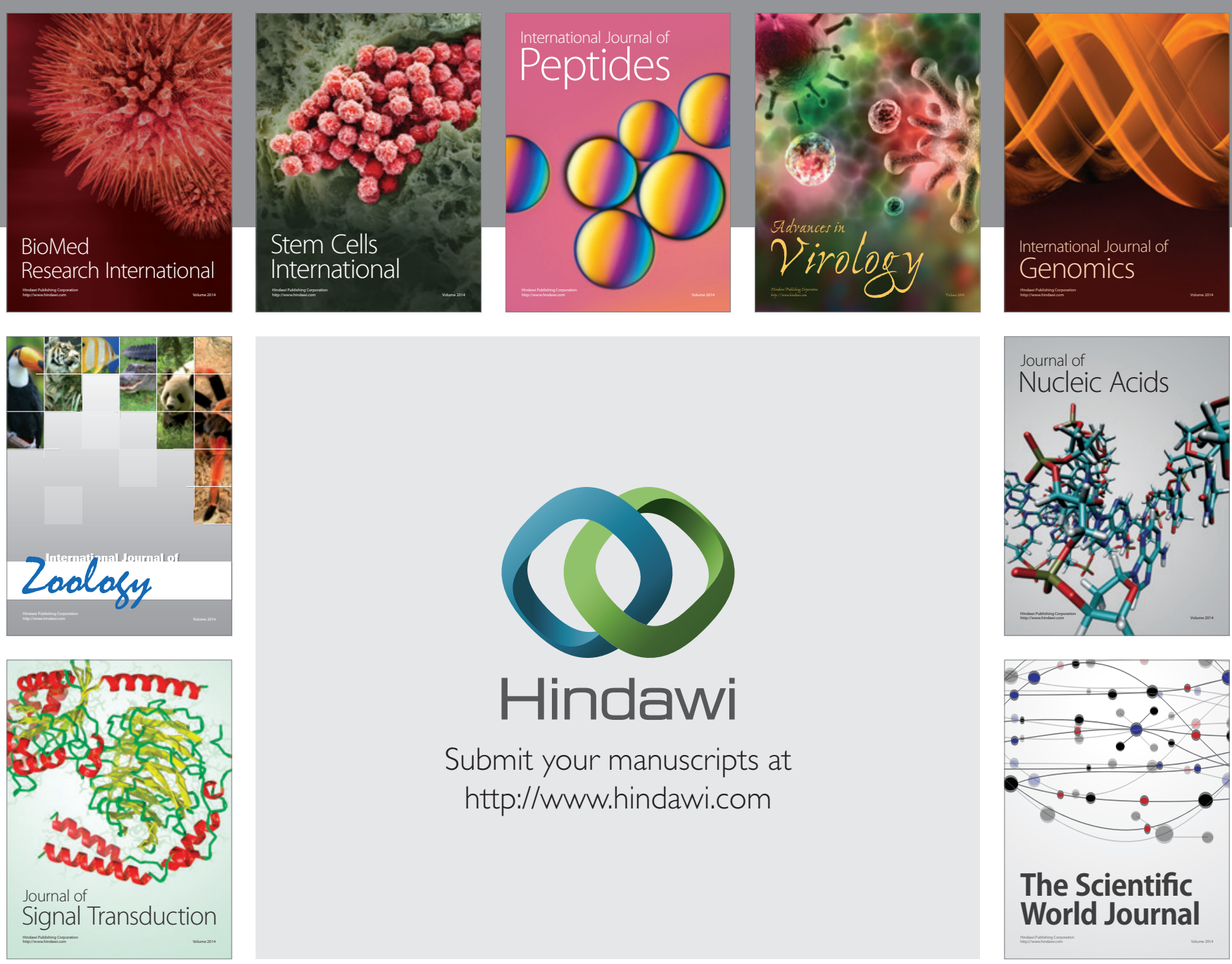

Submit your manuscripts at

http://www.hindawi.com
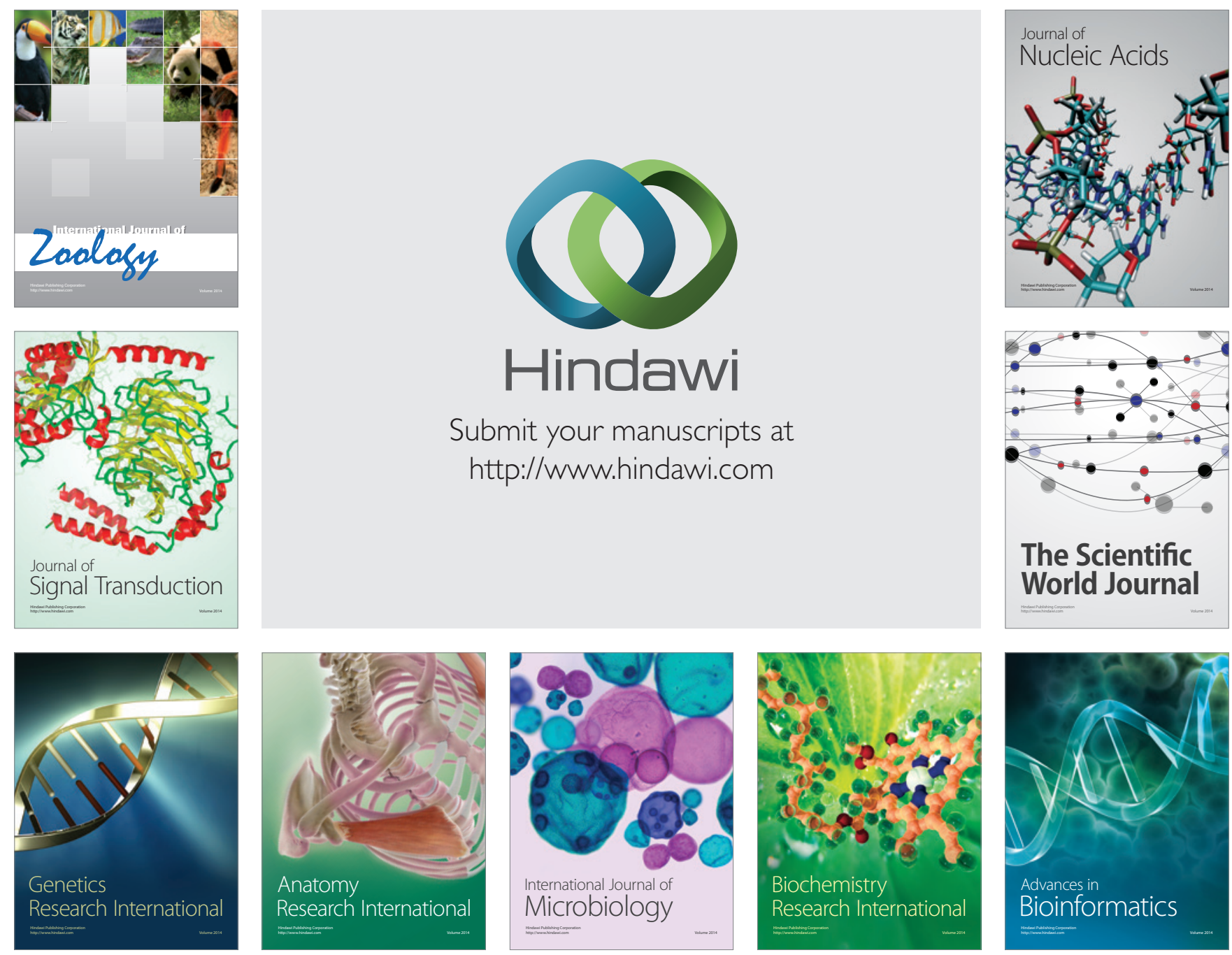

The Scientific World Journal
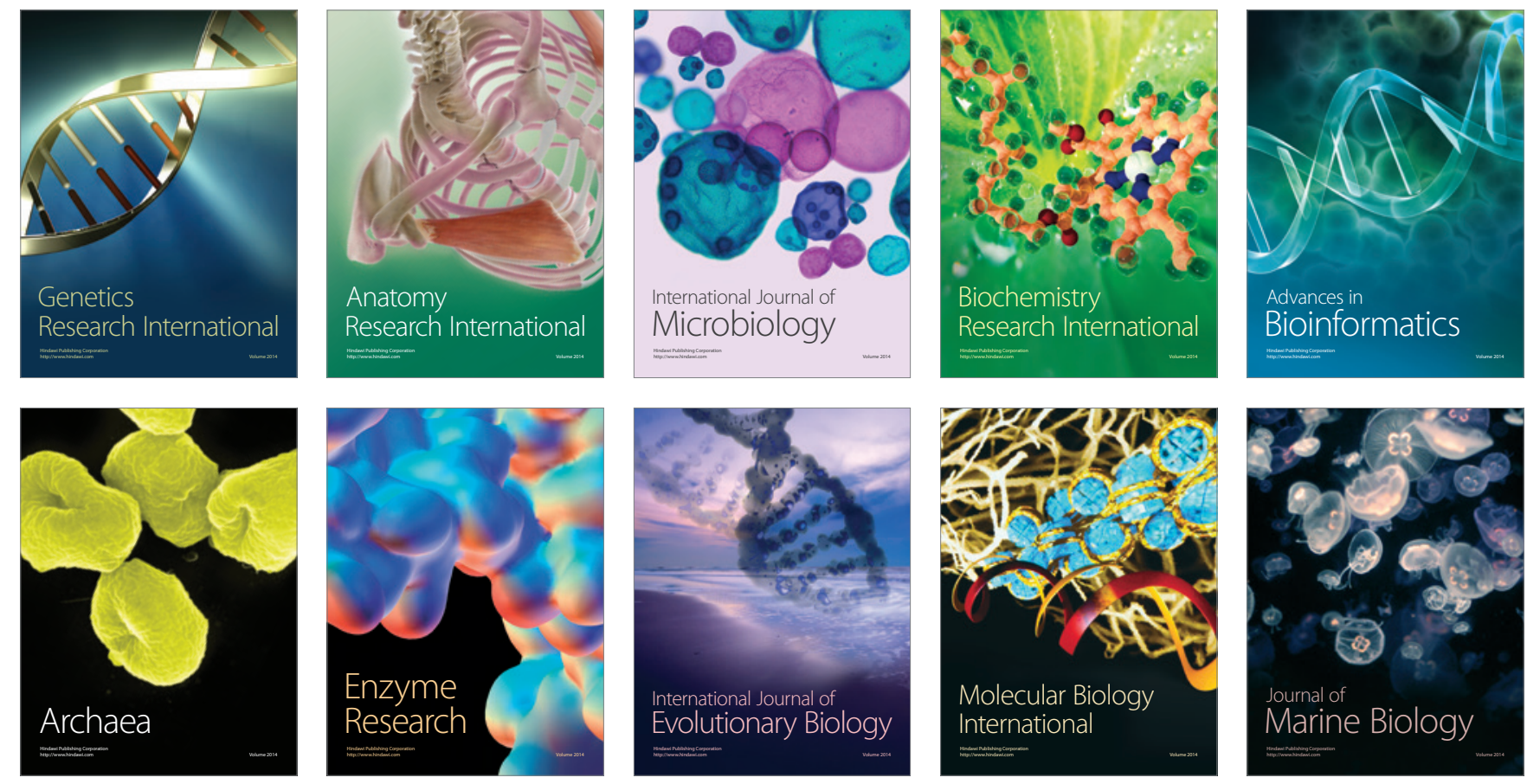